\title{
Changing fashion finding Changing Cities: Addressing the Gender Barriers
}

\author{
Anuj Behal \\ (Urban \& Regional Planning Student), Dimple Behal (Urban \& Regional Planner with Specialization in Environment)
}

Corresponding author: anujbehal1@gmail.com

Received: 20-08-2020

Revised: 23-11-2020

Accepted: 03-12-2020

\begin{abstract}
Fashion is fast these days, changing everyday every moment, maybe with a new fashion influencer coming on to the business or moreover to the social media. Though fashion is not new to the human civilization and nor its association is new with cities. Cities from the past has acted as grounds to the fashion, which is also possibly right since cities are a hub of Expression and freedom and so is fashion. Since the norms and definition of Fashion is evolving over time, it's acceptance in the city is becoming a question to worry about. With Gendered clothing norms being smashed each day, cities need to be more acceptable as well as well accessible to all those choices what an Individual makes. But where fashion is accepted universally as an act of expression, its practice today can create many hurdles and barriers for people, who are practicing it. This paper will address majorly the questions, does fashion acts as a barrier in accessing the cities? Does the evolution of fashion demands the cities to response in the similar way? Does the existing fashion trends needs special address to the Infrastructural needs in the city?
\end{abstract}

Keywords: Defining Fashion

\section{Defining Fashion}

Fashion as per oxford is defined as, "a popular or the latest style of clothing, hair, decoration, or behaviour". Similarly, as per the Cambridge definition it is, a style that is popular at a particular time, especially in clothes, hair, make-up, etc. But limiting the definition of fashion to these would not be favourable since fashion is more how a person feels. It could be a belief or value for a person and to someone it could be a way to express or simply freedom. Moreover, Fashion is an expression.

The clothes we wear from giving a visual appeal have a practical meaning. At least, they keep us warm and comfortable; they become part of our identity and character. What we wear, whether we like it or not, sends out signals that help people make an impression of us.

There are a number of avenues for fashion to be seen.
But is it a way of crossing the distinction between the inner state of someone and his outer appearance, an expression of your personality? Is it a visual picture of a social group or of someone's community? Or is there no more sense of dress than accordance with conventional standards? The truth is, maybe it's a combination of all three of them! Physical presence, a subtle means of communication, is a kind of vocabulary. Garments can't tell people that you're deep down, but at the first meeting they are part of the preliminary knowledge a person has about you. You put something, whether you're aware of it or not, out there. Fashion is exactly that only sometimes intentionally and very times unintentional.

How to cite this article: Behal, A. (2020). Changing fashion finding Changing Cities: Addressing the Gender Barriers. Int. J. Soc. Sci., 9(04): 235-242.

Source of Support: None; Conflict of Interest: None (क) 9 
Golda Meir, one of former Prime Minister of Israel once said, "Fashion is an Imposition, a rein on freedom". What else could define fashion better?

\section{Freedom}

Fashion gives Right to choose how we show ourselves to the world; freedom to blur the distinctions between men and women, old and young, wealthy and poor. It's more about how a person feels and how they wont to be treated or also it won't be incorrect to say that fashion not just justify Freedom but some beliefs and values that a person owns. This is how fashion plays an crucial role in representing how one person feels.

The question most people have for fashion is whether a person is dressing for their own self or for others? Most people like to believe that their decision about what to wear is a personal one, but is it free from outside interference, or the people are sending out messages for the sake of others, too? Possibly all of them.

As a kind of self-expression, fashion can make us feel empowered and associated with our inner selves. If the clothes we wear and the way we represent ourselves fit our personality, our identity and our mood, we will feel more comfortable. Such "self" signals are also sent to others, but there are elements of this concept that are more about belonging to or responding to demands within our culture and society in a specific group.

Where fashion is widely accepted as Expression and freedom it would not be incorrect too, that the fashion self-expression is a "myth". The sense of mode and dress is affected almost always by external factors; one of them is context. We speak within the limits of the context and make choices that are shaped by our history, practicality, the society in which we belong (or not and the manner in which we want to be viewed by others). For example: what a person want's to wear depends on the activity person is going to engage, I.e. a person going to an office will be dressing differently than going to a night club or an outing with acquaintance's.

Also, there are some socio-economiclimits that determine what people are able to wear or invest. Finally, when it comes to self-identity and trust and to other people's interpretation, mode and dress play an important part.
It is a type of self-expression that empowers one. So, what a person wants to wear cannot completely result from an act of free will - external influences and social norms can influence it too. Fashion is a phrase within a constraint and a context and knowing this helps us to get a deeper understanding of its function. It's not just about personality and the "self," it also reflects history, culture and a society's image in a particular place and time. Our self-expression is the flourish we offer it in its sense.

The relation between clothing, individuality and culture has also been explored by writers like Joanne Entwistle; the emphasis on personality often shadows the fact that our environment is almost always implicit. Industries and job standards are focused on assumptions regarding how much skin should be covered or revealed as well as on activities in different cases, including dress codes.

Hence it wouldn't be incorrect to say, fashion whereas equates its identity from a person's self-expression or freedom; it is not completely independent of the grounds where it is being practiced and largely depends on the socio-economic aspects of society.

This paper talks about talks about how fashion is an intriguing component in the today's cities and fashion being a freedom of expression is hindering the Right to access the city.

\section{Fashion and its relation to cities}

Fashion is not something that exists only in Dresses, said Coco Chanel once. Mega cities and conurbations have been controlled and reliant on the monetary system as a sign of prosperity and economic development, and fashion as a consumption-oriented phenomenon corresponds to metropolis characteristics. With the emergence of cities and the middle class, fashion as we know it originated in 14th century Europe. But also, fashion today is not just longer a product of urban life in contemporary cities; instead, fashion is a device to build and recreate urban space context. Hence both the cities and fashion today defines each other.

In the early $21^{\text {st }}$ century, style redefines the city today. It means that the phenomenon of fashion not only prescribes clothes for urban spaces; it affects town 
identity and the city landscape by constructing pictures of urban and urban life. Moreover, trendy ideas from world-class catwalks become popular across the streets of numerous towns and on the other hand, street fashion trends encourage designers to produce new collections. In other words, cities can be seen as a place for the phase of fashion.

\section{Urbanization leading to change in fashion choices}

Globally, more than 50 percent of the population lives in urban areas today, according to the World Bank. By 2045 , the urban population of the world will grow by 1.5 times to 6 billion. The planet has never seen urbanisation at the same pace as it does today. Modern China sees economic development much larger and quicker than the comparable urban development of the past, like Britain's own industrial revolution ("The Future of Fashion is Urban," 2018). India, too is struggling to reach the peak of its urbanisation growth. What this means is that the urban hubs of the world are now much more likely to be in large developing markets. And the same emerging markets are responsible for a larger and larger proportion of demand for clothing and fashion where good urban lifestyle is one of the major pull factors for people moving to the cities.

Fashion and its consumption is one of an inherent component of a better lifestyle. Therefore as buyers (immigrants) migrate to urban areas, the clothing requirements are changing and their tastes are changing. This transition can be especially important for consumers in emerging markets. According to Translate media, in 2018 urbanization is not only about moving into a more constructed environment, it is also about essential change to an individual's work and social life. Emerging market urbanization also converts workers into a more structured work environment from agricultural or casual employment. Not all employees end up wearing an attire, but may have to be dressed for their working environment in a particular way. Not only do urban workers have to turn up differently compared with their rural jobs and their life is also more complicated, which means they are more likely to have separate clothes for different occasions. This can include whole clothing collections for exercise and socialization.
Urbanization is also related to more sophisticated and knowledgeable customers so that they are more likely to gain brand recognition and information of what they purchase. Often cities are less traditional and more cosmopolitan than rural areas. Consumers can switch easily from using clothing manufactured from local (or home-made) fabrics produced on informal or small traders, to pursuing mass-produced clothing from formal stores and major shops with global supply chains.

Cities from the past have supported the notion of fashion friendly, fashion acceptable and fashion grounds. Hence, rapid urbanisation in emerging markets means that much of the new demand will come from city dwellers. Also, where fashion exhibits freedom, it requires grounds to exercise those freedom choices. These grounds are cities from where these barriers are breaking which could be seen from past.

\section{Fashion and the Gender norms: Past and Present}

Fashion has an effect on social class, trends and how clothing is also applicable to society. Clothing for both men and women has been culturally described in the past and spreads to the legs more in the present. Cultural norms and perceptions contribute to the sense of becoming a man or a woman and are closely related to appearance. But these fashion senses rather than serving any physical demand to any gender, moreover perceives the stereotypical norms of masculinity and femininity.
"The stereotypical masculine or feminine qualifications are not personality characteristics of individual men and women but socially constructed representations of gender, on the basis of what society expects of each sex".

According to (Akdemir, 2018) "Expectation of society and culture related to the biological structure of the individual carries some roles and this role also carries many gender stereotypes in it. But the individual can use the clothing style to express his or her gender identity which may not match the expectations of the community and society."

Before the $19^{\text {th }}$ century, fashion was not seen in the sense of gender: fashion as clothing was the only symbol of 
the social class. Later, the gender structure for dress representations became very important for the fashion study. Since then the idea of the feminization of fashion - as concerned women and women as well as men and masculinity - has been emerging and transformed by social economic, cultural shifts and has attracted the attention of scholars.

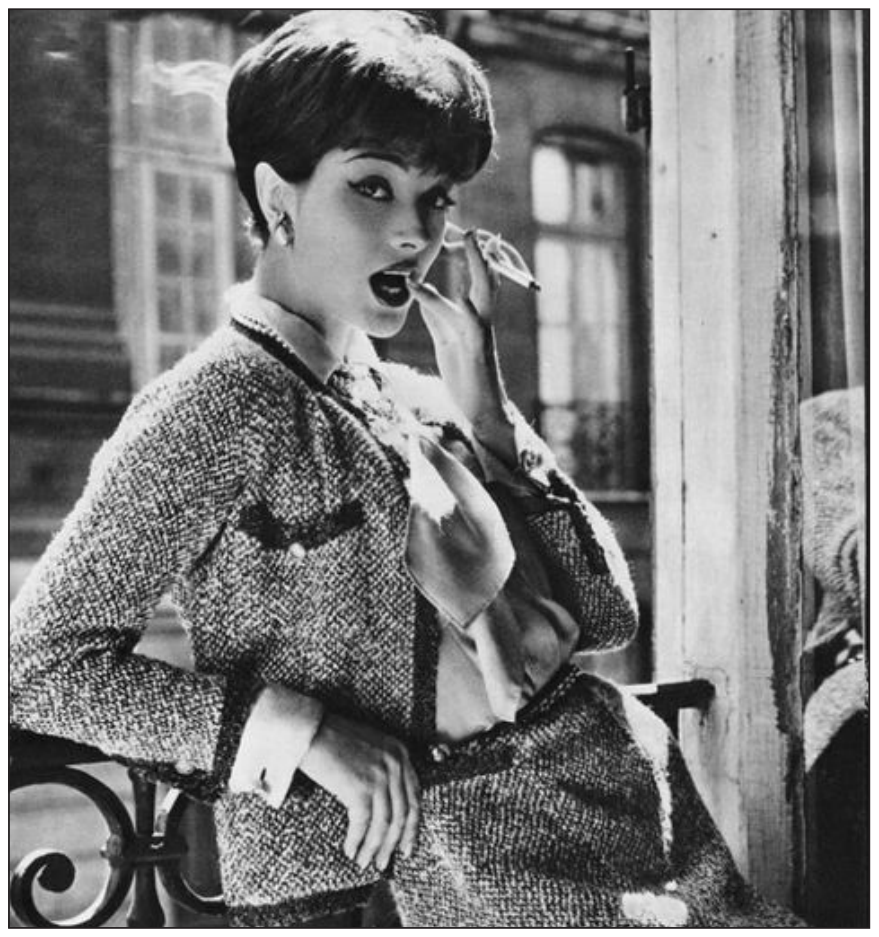

Fig. 1: Channel suit, a new fashion in the era of world war (Image source: website/elle)

World Wars I and II are seen worldwide as a fascinating age of fashion, society and politics. The fashion of the period was genuinely symbolic of activities taking place in the world in the most obvious way. Initially, Women in the Victorian England were bound to dressed up in tightly laced dresses with frocks and skirts to be floor touching and full of frills. These dressing norms were been supported by the fact that women are frivolous, delicate, passive and docile, where in the contrary men were expected to be extreme, strong, autonomous, and hostile. But due to rapid industrialization, in Britain, bulky, restrictive underwear, which had caused such a storm in the pages of women's magazines, was eventually discarded. Clothes became lighter, shorter and simpler. Many European women stopped wearing jewellery and expensive garments, featuring upper-class women mixed with other classes and social barriers shattered, and women started to look similar. Clothes became shorter during the First World War (19141918) due to practical necessity. By 1917, more than 700,000 women in Britain were working in ammunition factories. They wore a working outfit of blouses and pants with accessories such as scarves, which were later replaced by khaki jackets and caps. The bright colours disappeared from sight, and only the sober colours were worn while the war was going on. Thus the clothes were simpler and simpler. Skirts got shorter. Soon, pants became a crucial part of Western women's wear, allowing them greater freedom of movement. This was also the time when designers like Coco-channel came into the picture, idealizing the new industrial way of dressing for the women. There was a new simplicity in women's clothing that required designers and dayto-day women to tap into their creativity and make government mandates trendy.

The examples of fashion and stereotypes, and the influence of social norms over them is unending and even unending to the present. Women today in different parts of the world have to face various stigmas and stereotypes. From the length of their clothes, to what should be considered to be seen or not seen, what colour a man should wear, society has still been evolved from this fashion. This scenario is true to with the other spectrums of Gender and sexuality too where issues perceives to them in their own way. But what's important is fashion knows well how to cross these stereotypes and stand free.

Hence, Fashion from the past was been harnessed in the societal norms. Where somewhere colours are the way these stereotypes were imposed, at some other point they were imposed by the size or type of clothing and materials. But unleashing all these barriers fashion seems to be consistently growing in the settlements and most importantly in cities.

\section{Fashion today and the transforming norms: Gender fluidity affecting the fashion and cities}

From the above section it has been seen clear that the changing cities requires a changing set of fashion and 
this fashion comes with breaking the existing barriers and gender norms of the society. Likewise in case of the Industrialization in world war, contemporary cities of today still goes on breaking the existing social definition to femininity, masculinity and fashion. Fashion should be associated with what makes a person feel or what's most comfortable to them. Nothing less.

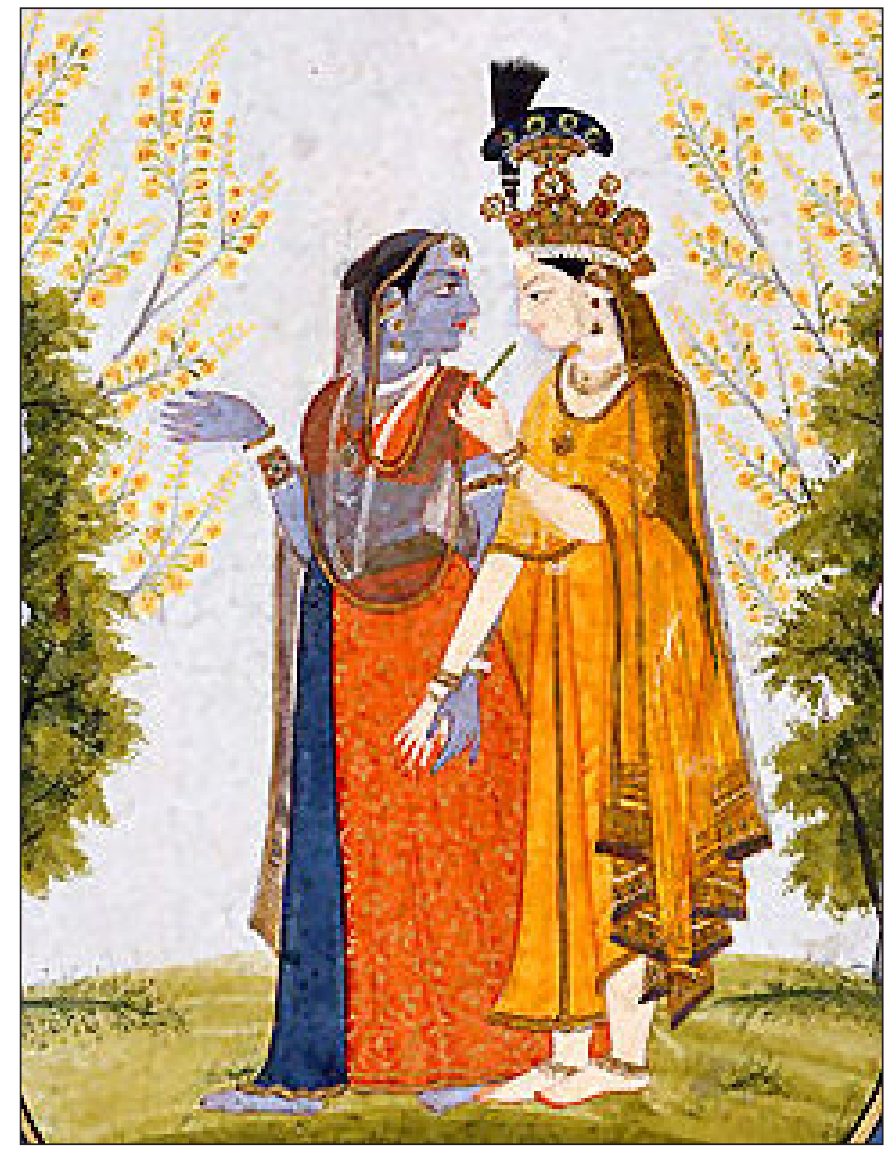

Fig. 2: Krishna Dressed as Radhika Rani, where Radha accessorised as Krishna (Image Information: India, Himachal Pradesh, Kangra. Title Radha and Krishna Exchange Clothes.

Date circa 1800. Museum Number M.80.232.4. Website:

\section{LACMA)}

Another similar example of breaking the accustomed fashion stereotypes could be seen in the Ancient India, or Bharat before. In the Hindu Religion, where Krishna the supreme personality of godhead, is considered to be the epic definition of Manhood. Likewise said by one of a greatest devotee of Krishna, Meera in conversation to Saint Roop Goswami, "Krishna is the only Param Purush in the universe and rest all are Braj Nari". This simply means that, the only man in the universe is Krishna himself and rest all are Prakriti (Nature). Prakriti is female and she is controlled by the Lord just as the activities of a wife are controlled by husband in the materialistic world. But what's strange is, even after Krishna being the supreme man; his portrayal is always feminine, breaking all the gender stereotypes of the Femininity and Masculinity. Where he enjoys dressing up as a man, he too enjoys his fashion being dressed completely as a women. Even in the present times, Temples in Mathura and Vrindavan, India portrays him as the same, as they dresses the idols of Krishna many times as Radha or Gopi (female energy) with all the traditional ornaments and Clothing, and also at some instances, been dressed up as both men and women at the same time. The figure 1 shows an interesting painting of Krishna depicting Krishna as Radha and Radha as Krishna.

What strange is today, when Krishna who is considered to be a Param Purush (Supreme man) loves flaunting his fashion in breaking the stereotypes of men and women, India thereafter and many much today has also accepted these norms defining boundaries for men and women.

The stereotypes to gendered nature of fashion still perceives in India. People in the many parts of the country still believe in the notion of certain gender dressing up in a certain way, which is quite unexpected, since the cultural practices in the past (possibly of Krishna) could not help them to get a lesson in there modern life. The patriarchal norms still remains to continue, and are majorly imposed with toxic masculinity and patriarchy in the society, which believes they can control.

But apart from all those social barriers many people and especially from the LGBTQIA+ community dares to believe in this idea of self-expression. Where the people from the community still faces a lot of humility and hatred, breaking the Gender norms of fashion. Fashion today is Gender Bending. It moreover focuses today on breaking the existing stereotypes of men and women, basically the Cis-genders to a complete spectrum of SOGI. As per National Geographic, in the current situation of LGBTQIA+ rights and the influence of social media in the growth and self-identification of 
groups, the gender and fashion issue takes on a specific immédiacy.

Today, the sense of fashion is transforming where more of the brands internationally going for unisex fashion, it is coming more equivalent and balanced. Some pieces of clothing are for men and some can only be worn by women, these are the sentences that are a thing of the past now. High-end couture brand like Gucci has also joined this club and is trying to shatter the stereotypes related to clothing while giving a loud and clear message with their tartan dress for men.

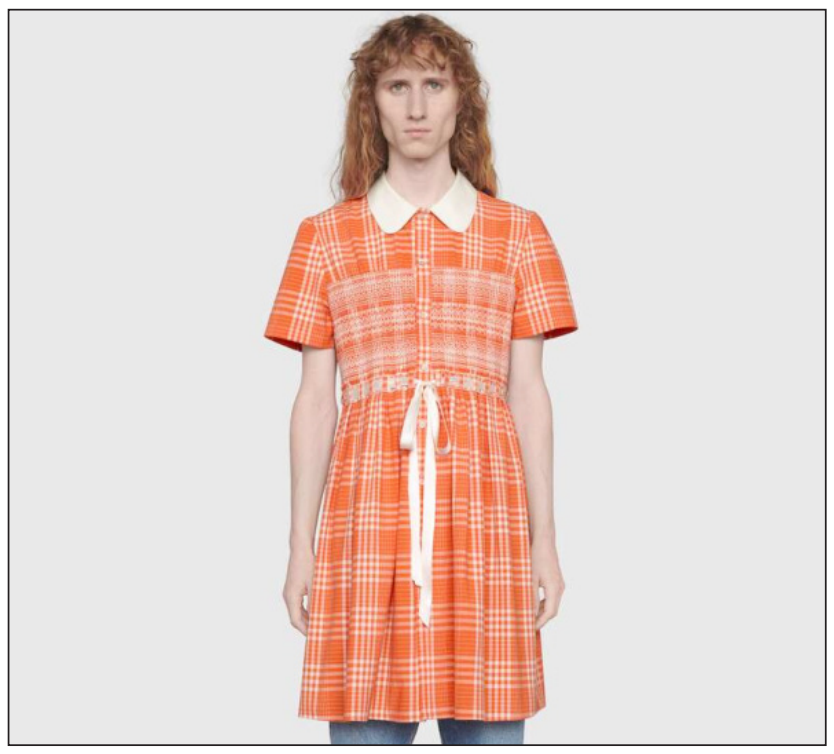

Fig. 3: Gucci's Tartan dress for men, Image Source: website/ Gucci

Gucci explored gender fluidity with clothes in their Fall Winter 2020 collection. The fashion house released a grunge look for men from the 90s that was aimed at disrupting the toxic stereotypes that mould masculine gender identity." Inspired by grunge looks from the '90s and modelled over torn denim trousers, this tartan smock in delicate colours represents the definition of fluidity explored for the fall winter 2020 fashion show, undermining the toxic assumptions that shape male gender identity" said the product description.

Unisex fashion is becoming the upcoming trend with more and more fashion houses emphasizing on blending the closets of men and women (likewise Gucci did). Also due to the wave of social media, Influencers all across the internet makes it easy to find people (who might not conform to standards of things like gender in fashion) their real sense of fashion. This all simply is making the fashion more easy and relatable to people today.

\section{Fashion as a barrier to access Cities}

When cities Industrialized, it brought change in fashion for women today, but when today fashion is getting Gender fluid how does the cities are responding? This question is important to address, since fashion today is transforming at a rapid pace and consistently challenging the existing notions as seen in the previous section. With fashion expression getting vibrant and bold, theses Expression comes with cost. While today's restrictions are blurry or less restrictive, societal pressures still determine the boundaries of whether we feel at ease - for better or for worse. Where fashion has been emphasized as a strong expression, when the expression doesn't seem acceptable to society, it faces hate and exclusion in the cities, even today. There are many instances which people encounter leading various restrictions to their fundamental rights of movement and freedom because of exercising their real sense of fashion (even which is beyond the norms of a society).

The barriers to fashion in the city are not witnessed at a certain place, but there are complete set of activities and services when Fashion becomes a barrier to perform. These could be understood with the following Incidents quoted while interviewing various people for this research in the Indian cities. The question of "Fashion is becoming a Barrier in the city" to all the respondents brought different answers and variable issues in front of us. While for many the issue is not worthy but there are people who are victims of these events in some or the other way when fashion became the hurdle to their liberty.

One of a Cis-Gay person Interviewed for this research said:

"I've always felt discomfort in wearing extravagant clothes, or a nose ring, or nail polish in the metro due to the fear that I will be stared, groped, or worse assaulted. I have seen instances of harsh judgments in the metro and don't want to be a victim of any of those. 
This sense of felling that how will people be reacting to their fashion sense/choice is disturbing and pushes them to the existing gender and fashion norms of Binary gender. Though even when a person feels completely free to undergo there fashion choices, People "carrying the notions of the society "in the city are standing out to challenge them. Another person living in a metropolitan of Delhi encountered,

\section{"I was been prohibited using the Public washroom at a metro station in Delhi by the watch guard of the washroom. When I asked him the possible reason to the same, he answered, you can make the men inside feel uncomfortable for the possible reason that you are wearing heels and eyeliner. I was stunned to his reaction and just choose to make an issue out at the public place and left. But this ultimately made me not wear heels back whenever I'm commuting with the transit again"}

Also many times during security checks encountered at various spots in cities like, Shopping malls, Transport stations or other public places, many people are misgendered on the aspect of their physical appearance which usually come from the fashion too. These incidents of misleading gender of someone can create a long mental impact to the person and could provoke the person to challenge there self if they are less or doing something wrong.

The list of places in cities where people encounter obstacles are not just limited to a certain places, but it varies from incidents to various spots. It could vary from getting into a public transport, using a public place like Park or even a shopping mall, finding an occupation or right workplace, finding a house to rent or own, enrolling into an education institutes, or even the bare minimum function of accessing or using a Public Toilet. The list is ever ending. Fashion choice or even gender preferences should not come in a way to access the infrastructure which is made for "all".

Some of the other Incidents encountering hate and fashion Stereotypes by various people interviewed are:

\footnotetext{
A famous Trans-women Influencer and activist from Karnataka once shared on her social media an incident, when she was prohibited to get into class by one of her professor just because she choose to wear a nose pin.
}

A Cis-man quoted, "Finding a house to me was a big trouble in Delhi which I never thought. What's more disturbing for me was the reasons, which were my blonde hairs and my choice to be a cross-dresser. The landlord was either simply refused me to lend the property or was just asking me to pay double of the actual rent which they would be charging from any other person. When asking for the reason they said either you choose to dress 'normal' or pay the double of the charges since you will put our property value down. Finally, I had no choice and choose to leave in a residency where I don't go for Cross-dressing in my usual life".

A man from Manipur told me how the headmaster at the school where it used to teach, asked him to dress in a specific way:"..the principal, and the rest of the teachers told me to wear a saree or salwaar kameez (a Indian female attire). They said that if I were to dress up like men, the children would also turn up like me".

"I usually get some stares if I wear something overtly printed or brightly coloured in the metro. I never bothered that this thing is basically associated with my fashion or clothes but have realized that since I started going to my new job in formal shirts and pants, none of that happens." said a Cis- Gendered Gay man.

Violence and harassment too sometimes accompanies with the verbal abuse and inacceptance. But what's shocking is these incidents come up from the metro cities of the nation. With so many things Fashion and cities have in common, cities today needs to match the pace of dynamism of the fast moving fashion. With cities constituting of its people, they need to be more acceptable and cities today need to be more Inclusive for whatever personal choice a person makes.

\section{CONCLUSION AND WAY FORWARD}

The relation between fashion and cities is never ending, nor is the fashion going to escape from the cities which are currently urbanizing at a tremendous rate. This increase in diversity regarding gender representation has a positive impact on both the perception of the trans and non-binary communities but still there is a long way to go. The city Planners and the policy makers need to reimagine the cities of fashion and the cities of 
future, where no one is left behind. Accessibility must be addressed in all its complexity, including the physical environment, travel, information and communication, and facilities. The emphasis is no longer on the legal personality and the public or private nature of those who own houses, transport facilities, cars, information and communications, and services. As long as goods, products and services are open or made available to the public, they must be accessible to everyone, regardless of whether they are owned and/or delivered by a public body or a private organization. Fashion, gender or sexual Identity should not come in the way of accessing the basic rights. Likewise also said by Pierre Davis, "This is not just fashion, this is a lifestyle and it needs to be taken seriously."

\section{REFERENCES}

Akdemir, N. 2018. Deconstruction of Gender Stereotypes Through Fashion. European Journal of Social Science Education and Research, 5(2): 185.

Bhagavad Gita. (n.d.). Retrieved from https://www.bhagavad-gita. us/
Hawley, D. (n.d.). Top Non-Binary \& Gender-Neutral Influencers To Follow Now. Retrieved from Viral Nation website: https:// www.viralnation.com/blog/top-non-binary-gender-neutralinfluencers-to-follow-now/

Newman, C. 2019. Gender-bending fashion rewrites the rules of who wears what. Retrieved December 10, 2020, from National Geographic website: https://www.nationalgeographic.com/ culture/2019/03/gender-bending-fashion-rewrites-rules-whowears-what/

Skivko, M. 1986. Fashion in the City and The City in Fashion: Urban Representation in Fashion Magazines. In Bauhaus-University Weimar. https://doi.org/https://doi.org/10.25643/bauhausuniversitaet.3726

The Future of Fashion is Urban. 2018. Retrieved December 10, 2020, from TranslateMedia website: https://www.translatemedia. com/translation-blog/future-fashion-urban/ 